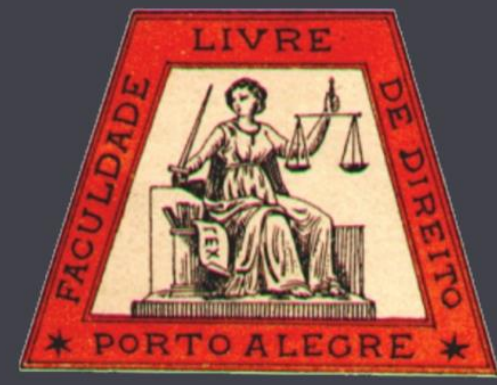

\title{
Globalização e superação da soberania moderna
}

Globalization and the overcoming of modern sovereignty

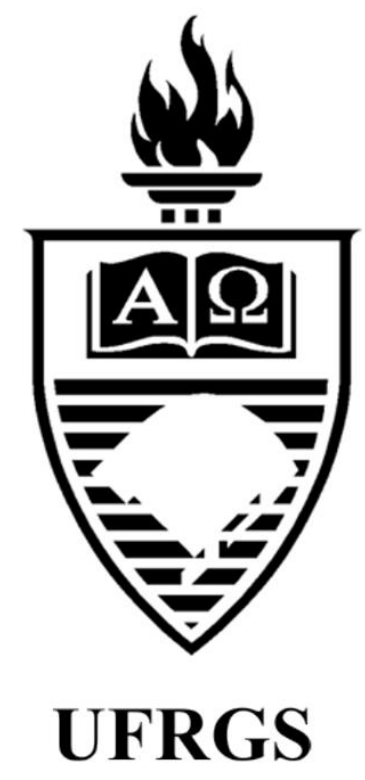

\author{
Fabrício Wloch \\ Universidade do Vale do Itajaí \\ Juliana Nunes Vizzotto \\ Academia Judicial do Estado de Santa Catarina
}

Revista da Faculdade de Direito da UFRGS

ISSN: 0104-6594 Site http://seer.ufrgs.br/revfacdir

Faculdade de Direito da UFRGS - Rua Riachuelo, 1317 - Centro - Porto Alegre - RS - Brasil

CEP - 90010-271 - Telefone: +55 5133083118 - Site http://www.ufrgs.br/direito/ 


\title{
Globalização e superação da soberania moderna
}

\author{
Globalization and the overcoming of modern sovereignty
}

Fabrício Wloch*

\author{
Juliana Nunes Vizzotto ${ }^{* *}$
}

\begin{abstract}
REFERÊNCIA
WLOCH, Fabrício; VIZZOTTO, Juliana Nunes. Globalização e superação da soberania moderna. Revista da Faculdade de Direito da UFRGS, Porto Alegre, n. 34, p. 82-98, ago. 2016.
\end{abstract}

\begin{abstract}
RESUMO
Este artigo investiga a superação da Soberania moderna no mundo globalizado. A importância do tema é que, diante da flexibilização da Soberania, elementos externos passam a influir diretamente nas decisões internas dos países e, consequentemente, na vida do povo. É apresentado em quatro itens: Estado Moderno; Soberania; Globalização; e superação da Soberania moderna. Chegou-se às seguintes conclusões: a Soberania é um elemento do Estado Moderno que vem sofrendo adaptações frente aos atuais fenômenos sociais, especialmente a Globalização, que acarreta crise no Direito, na Democracia e no próprio modelo de Estado. Pensa-se na desconstrução do Estado Moderno diante da superação do conceito de Soberania e admissão do Direito Transnacional para incluir, num modelo de cooperação e solidariedade, todas as normas que regulam atos ou fatos que transcendem fronteiras nacionais. No que se refere ao procedimento metodológico, o trabalho foi desenvolvido sob o método indutivo. A pesquisa foi bibliográfica e documental.
\end{abstract}

\section{PALAVRAS-CHAVE}

Estado Moderno. Soberania. Globalização. Direito Transnacional.

\section{ABSTRACT}

This article investigates the overcoming of modern sovereignty in a globalized world. The relevance of this subject is that, in the face of the easing of sovereignty, external elements are now directly influencing the internal decisions of countries and consequently the life of the people. It is presented in four items: the modern State; sovereignty; globalization; and the overcoming of modern sovereignty. We came to the following conclusions: Sovereignty is an element of the Modern State that has suffered adaptations in the face of current social phenomena, especially globalization, which entails crisis in Law, in democracy and in the own State model. It is thought in the deconstruction of modern State in the face of the overcoming of the concept of sovereignty and the admission of Transnational Law in order to include, in a cooperation and solidarity model, all norms governing acts or facts that transcend national borders. With regard to the methodological approach, the work was carried out under the inductive method. The research was bibliographic and documental.

\section{KEYWORDS}

Modern State. Sovereignty. Globalization. Transnational Law.

\section{SUMÁRIO}

Introdução. 1. Estado Moderno e Soberania. 1.1. Elementos do Estado Moderno. 2. Globalização. 3. Superação da Soberania. Conclusão. Referências.

\footnotetext{
* Doutorando e Mestre em Ciência Jurídica do Programa de Pós-Graduação Stricto Sensu em Ciência Jurídica - PPCJ da Universidade do Vale do Itajaí - Univali, Brasil.

** Especialista em Direito Constitucional pela Univali e em Gestão Organizacional e Tecnologia em Recursos Humanos pela Universidade Federal de Santa Catarina, UFSC; Bacharel em Direito pela Universidade de Passo Fundo, UPF, Brasil.
} 


\section{INTRODUÇÃO}

O problema enfrentado é que, diante da flexibilização da Soberania, elementos externos passam a influir diretamente nas decisões internas dos países e, consequentemente, na vida do povo.

Parte-se da hipótese de que os processos econômicos e sociais do progresso civilizatório levam à crise do Direito Nacional e da Democracia com a consequente desconstrução do Estado Moderno. Daí surge a necessidade de uma tutela de bens jurídicos acima de fronteiras e desvinculada da delimitação precisa do âmbito territorial.

Então, o presente artigo tem como objeto a Soberania do Estado Moderno à luz do fenômeno da Globalização. Tem como objetivo específico investigar a desconstrução e a alternativa ao Estado Moderno diante do fenômeno da Globalização e sua interferência na Soberania.

$\mathrm{Na}$ primeira fase de pesquisa, a decisão, operou-se com o Referente ${ }^{1}$ de descrever o Estado Moderno e seus elementos, notadamente a Soberania e sua flexibilização frente ao fenômeno da Globalização. $\mathrm{Na}$ segunda fase da investigação, realizou-se a busca de dados, especificamente fundamentos doutrinários. $\mathrm{Na}$ terceira fase de pesquisa, de tratamento de dados recolhidos, foram correlacionadas sob o método cartesiano as formulações doutrinárias em função do Referente eleito. A quarta fase da pesquisa culminou neste relatório de pesquisa, que aponta as conclusões obtidas.

\footnotetext{
1 A perspectiva conceitual da Técnica do Referente foi extraída de: PASOLD, Cesar Luiz. Metodologia da Pesquisa Jurídica: Teoria e Prática. 13. ed. rev. atual. e ampl. Florianópolis: Conceito Editorial, 2015. p. 57-66.

2 Ibid., p. 85.

3 CAETANO, Marcello. Manual de Ciência Política e Direito Constitucional. 4 ed. Lisboa: Coimbra Editora,1963. p.109.

4 BLUNTSHLI, J. Johann Kaspar. The theory of the State. Oxford: Clarendon Press,1898. p. 19.
}

Inicialmente traz-se aspecto histórico e de formação do Estado Moderno; depois, discute-se a Soberania nacional; em seguida, analisa-se a Globalização; e, finalmente, a superação da Soberania moderna e as crises que ela ocasiona, com a proposta do Direito Transnacional.

No que se refere à metodologia ${ }^{2}$, este trabalho concentrou-se na área de Constitucionalismo, Transnacionalidade e Produção do Direito, foi desenvolvido sob o método indutivo e operacionalizado com as técnicas do referente, da categoria, do conceito operacional mediante pesquisa bibliográfica e documental.

\section{ESTADO MODERNO E SOBERANIA}

O Estado pode ser entendido a partir de vários contextos, segundo a teoria que o definiu ou lhe deu atribuição. Mais ainda: o Estado seria o resultado da forma de organização da Sociedade, seria a "Sociedade política"3. "Não é produto da natureza, mas sim fruto do trabalho do homem"4.

Dallari 5 defende que "a denominação Estado, significando situação permanente de convivência e ligada à Sociedade política aparece pela primeira vez em 'o Príncipe' de Maquiavel, escrito em 1513”. Nessa mesma linha, Bobbio ${ }^{6}$ diz: "É fora de discussão que a palavra 'Estado' se impôs através da difusão e pelo prestígio do Príncipe de Maquiavel". E Heller ${ }^{7}$ quando declara: "o Príncipe' introduz na literatura o termo Estado para designar um novo status político".

5 DALLARI, Dalmo de Abreu. Elementos de Teoria geral do Estado. 19. Ed. São Paulo: Saraiva, 1995. p. 43.

6 BOBBIO, Norberto. Estado governo e Sociedade. Trad. Marco Aurélio Nogueira. 4.Ed. Rio de Janeiro : Paz e Terra, 1992. p. 65.

7 HELLER, Hermann Teoría del Estado. 2.Ed. Tradução de Luis Tobio. México: Fondo de Cultura Económica, 1998. p. 170. Título original: Staatslehre. 
Cronologicamente, Jellinek ${ }^{8}$ apresenta a seguinte tipologia: oriental, grego, romano, medieval e Moderno. Já Dallari ${ }^{9}$ apresenta a seguinte sequência histórica: antigo, grego, romano, medieval e Moderno. Pasold 10 acrescenta um sexto tipo que é o Estado contemporâneo.

O Estado Moderno, que é o que interessa para a presente pesquisa, surge diante do inconformismo dos senhores feudais com as exigências dos monarcas, que impunham tributação indiscriminada e espírito de guerra constante, o que só causava prejuízo à vida econômica e social do Estado medieval ${ }^{11}$. Na afirmação de Grillo"12: "É o Estado absoluto, que surge como estágio inicial do Estado Moderno e é ele que aparece analisado nas obras de Maquiavel, Bodin e Hobbes, bem como de Filmer".

Para Soares ${ }^{13}$ :

O marco teórico para compreensão do Estado absoluto advém, pois, da leitura dos clássicos, como Maquiavel, Hobbes e Bodin, que justificaram jurídica e ideologicamente o absolutismo, ao captarem o triunfo do Estado sobre os poderes intermediários.

8 JELLINEK, Georg. Teoría General Del Estado. Tradução de Fernando de Los Rios. Buenos Aires: Albatroz,1978. p. 215-220. Título original: Allgemeine Staatslehre.

9 DALLARI, Dalmo de Abreu. Op.cit., p.59.

10 PASOLD, Cesar Luiz. Função Social do Estado Contemporâneo, p. 29.

11 DALLARI, Dalmo de Abreu. Op.cit., p. 60.

12 GRILLO, Vera de Araújo. A separação dos poderes no Brasil: Legislativo versus Executivo. Blumenau/ Itajaí: Editora Edifurb e Editora Univali, 2000. p. 16

13 SOARES, Mário Lúcio Quintão. Teoria do Estado: novos paradigmas em face da Globalização. 4. ed. São Paulo: Atlas, 2011. p. 78.

14 CRUZ, Paulo Márcio Cruz. Política, poder, ideologia e Estado contemporâneo. Florianópolis, Diploma Legal. 2001. p. 61.

15 A Paz de Vestefália, ou acordo de Vestefália foi o acordo feito entre os países europeus envolvidos na Guerra dos Trinta Anos. Engloba uma série de acordos entre países europeus - o conflito envolveu desde Alemanha, países escandinavos até a Espanha, e o modelo de acordos e tratados entre essas nações é considerado por muitos um dos marcos da diplomacia e do direito internacional moderno. $\mathrm{O}$ tratado foi negociado durante três anos pelos representantes dos católicos e protestantes, que eram basicamente as duas
Na busca de modificar essa situação, e baseadas em princípios liberais, democráticos e nacionalistas, a classe burguesa iniciou a primeira das revoluções modernas, os revolucionários passaram a defender o princípio da Soberania popular e igualdade de direitos. Estas revoluções foram $\mathrm{o}$ ponto de partida para o Estado Moderno ${ }^{14}$. Essa busca pela unidade do Estado foi corroborada com a assinatura do tratado de paz de Westfália ${ }^{15}$.

\section{No mesmo sentido, Rifkin pondera:}

\begin{abstract}
El reconocimiento formal del derecho soberano de los Estados territoriales en el derecho internacional se dio en la forma de un acuerdo de paz en 1648 que puso fin a la Guerra de los Treinta Años entre luteranos, calvinistas y católicos. La Paz de Westfalia reconocía las diferencias irreconciliables entre las diversas sectas del cristianismo, otorgaba a las autoridades territoriales potestad sobre las cuestiones religiosas dentro de su jurisdicción y limitaba el derecho de otros países a intervenir en lo que a partir de entonces se consideraría un asunto interno de cada país. Aunque los puntos esenciales de la Paz de Westfalia fueron modificados en los tres siglos posteriores, siguieron siendo prácticamente los mismos hasta el final de la Segunda Guerra Mundial ${ }^{16}$.
\end{abstract}

partes envolvidas na Guerra dos Trinta Anos, reunidos em Münster (onde tinha precedência a França católica) e em Osnabrück (onde tinha precedência a Suécia protestante). As conversações de paz, iniciadas em 1644 em Münster e Osnabrück, envolviam também o fim da guerra de oitenta anos entre Espanha e Países Baixos. O tratado de paz entre Espanha e Países Baixos foi assinado em 30 de janeiro de 1648; em 24 de outubro do mesmo ano foi assinado o tratado de paz entre Sacro Império Romano-Germânico, os outros príncipes alemães, a França e a Suécia. Os tratados foram concluídos nessas duas cidades da Westefália. "O processo de criação dos Estados europeus culminou nos tratados de Westefália (1648) que selam a ruptura religiosa da Europa, o fim da supremacia política do Papa (mesmo nos países católicos) e a divisão da Europa em diversos Estados independentes, cada qual compreendido dentro de fronteiras precisas. À república Chrisitana sucede, assim, a um sistema de Estados soberanos e iguais" MIRANDA, Jorge. Teoria do Estado e da Constituição. 2 ed. Rio de Janeiro: Forense, 2009. p. 25.

16 "O reconhecimento formal do direito soberano dos Estados territoriais no direito internacional se deu na forma de um acordo de paz em 1648, que pôs fim à Guerra dos Trinta Anos entre luteranos, calvinistas e católicos. A Paz de Westphalia reconhecia as diferenças irreconciliáveis 
Gradativamente o Estado foi assumindo as feições que possui hoje. Na definição de Kelsen ${ }^{17}$ : "Uma ordem jurídica relativamente centralizada, limitada no seu domínio espacial e temporal de vigência soberana ou imediata relativamente ao Direito Internacional e que é, globalmente ou de um modo geral, eficaz".

Em consonância com o acatado, o Estado Moderno surge então com a superação do estado absoluto e a dominação de poderes intermediários representados pela burguesia e pelos senhores feudais, que encarnam o império da Soberania popular e da igualdade de direitos em busca da unidade de instrumentalização de administração e independência em relação ao direito internacional.

\subsection{Elementos do Estado Moderno}

Comumente se apresenta como elementos do Estado: o povo, o território e o poder político (Soberania). Elementos estes que caracterizam o "Estado Nacional soberano que surgiu na Europa e espalhou-se como modelo pelo mundo" 18 acompanhando os processos de colonização.

O território ${ }^{19}$ é a delimitação do espaço físico do Estado. Logo, não existe um Estado sem território; o território delimita a ação soberana do Estado, é o espaço físico ocupado, a zona espacial. Na concepção Kelseniana, “o território se torna limite ou esfera de validade espacial da ordem jurídica nacional e o povo o limite ou

\footnotetext{
entre as várias seitas do cristianismo, outorgava às autoridades a respeito de assuntos religiosos dentro da sua jurisdição e limitava o direito de outros países intervir no que então se consideraria um assunto interno de cada país. Embora o essencial da Paz de Westfália tenha sido modificado nos três séculos seguintes, menteve-se-se praticamente o mesmo até o final da Segunda Guerra Mundial" (tradução livre) Barry Hindess, Neo-Liberalism and the National Economy, en M. Dean y B. Hindess (comps.), Governing Australia: Studies in Contemporary Rationalities of Government, Cambridge, Cambridge University Press, 1988, págs. 210-226; in RIFKIN, Jeremy. La Civilización Empática, p.287
}

esfera pessoal da validade da ordem jurídica nacional" 20 .

O povo ${ }^{21}$ é o elemento pessoal para a constituição e a existência do Estado. É o indivíduo reconhecido como pessoa, elemento vivo do Estado. Povo é o conjunto de pessoas que vivem sob a tutela do Estado em certo lugar. População é quantitativo, e povo é qualitativo. Os direitos são para o povo que é membro partícipe da Sociedade e do Estado.

Atualmente, essa ideia de povo e de território vem sendo ultrapassada por causa da atual melhor mobilidade das pessoas $\mathrm{e}$ as prementes teorias de desconstrução do Estado. Tenha-se como exemplo a formação de comunidades internacionais que flexibilizam o exercício da cidadania mesmo para os estrangeiros que residem no país; é o caso da União Européira e da Unasul. Esta última visa a fortalecer as relações comerciais, culturais, políticas e sociais entre as doze nações da América do Sul - Argentina, Bolívia, Brasil, Chile, Colômbia, Equador, Guiana, Paraguai, Peru, Suriname, Uruguai e Venezuela -, além da participação, como observadores, de dois países da América Latina: México e Panamá. É de grande importância para a integração desses países, pois, através da implantação de uma zona de livre comércio, haverá maior flexibilidade nas relações comerciais, circulação de pessoas e mercadorias. Outro aspecto relevante é a união dos dois blocos econômicos da América do Sul (Mercosul e CAN - Comunidade Andina), além

17 KELSEN, Hans. Teoria Pura do Direito. Tradução de João Baptista Machado. 7. Ed. São Paulo: Martins Fontes, 2006. p. 321.

18 MIRANDA, Jorge. Teoria do Estado e da Constituição, p. 32

19 DALLARI, Dalmo de Abreu. Elementos de Teoria geral do Estado, p. 81-84.

20 SOARES, Mário Lúcio Quintão. Teoria do Estado, p. 89.

21 CAETANO, Marcello. Manual de Ciência Política e Direito Constitucional. 4 ed. Lisboa: Coimbra Editora,1963. p. 103. 
da possibilidade de criação de uma moeda única, denominada "pacha".

Por fim, a Soberania, para Dallari ${ }^{22}$, é o centro unificador da ordem, o núcleo de vontade e controle do Estado, que dirige a Sociedade aos seus fins comuns dentro da ordem. Como ao Estado não se devem sobrepor outros poderes ou centros de comando, diz-se que a Soberania é o poder incontrastável do Estado. Caetano ${ }^{23}$ utiliza a ideia de que Soberania é o "poder político supremo independente". A Soberania seria para ele a "plenitude do poder político" por entender que pode existir Estado não soberano. Isso se passa, segundo ele, com os "Estados federados e os Estados protegidos".

Um Estado federado difere de Estado soberano, haja vista ter transferido parte de seus poderes soberanos para o governo federal. Um Estado federado tem competência administrativa sobre um território geográfico definido. Exemplos de países que são subdivididos por estados federais são Brasil e Índia. Já o Estado protegido, ou protetorado, é um território autônomo que é protegido diplomática ou militarmente contra terceiros por um Estado ou ente mais forte. Para tanto, o protetorado geralmente aceita obrigações específicas, dependendo da natureza de seu relacionamento, porém mantém a soberania formal, e continua a ser um Estado sob a lei internacional. Como exemplos, cita-se que a Agência de Proteção Ambiental dos Estados Unidos usa o termo protetorado quando se refere a regiões insulares daquele país, tais como Porto Rico e as Filipinas.

22 DALLARI, Dalmo de Abreu. Op.cit., p. 68-69.

23 CAETANO, Marcello. Op.cit., p. 108-109.

24 "Soberania do Estado é geralmente entendida como o monopólio de autoridade do Estado sobre um determinado território, demarcado por fronteiras geográficas razoavelmente estabelecidas" (tradução livre) SASSEN, Saskia. Bordering Capabilities versus Borders: Implications for National Borders. 30 Michigan Journal of International Law (2008-2009). p. 567-597.

25 "Como todas as pessoas livres que reivindicaram Soberania sobre seus bens pessoais, o Estado nacional também reivindicou um direito de Soberania sobre o
No entanto, "Escritório de Assuntos Insulares" (Office of Insular Affairs), responsável pela administração dessas áreas, usa sutilmente o termo "áreas insulares" para se referir a esses territórios.

Voltando ao estudo da Soberania, Sassen escreve: "State sovereignty is usually understood as the State's monopoly of authority over a particular territory, demarcated by reasonably established geographic borders" 24 .

A Soberania traz como elemento essencial a identificação de uma autoridade suprema. Suas alterações estão no modo de exercício da autoridade, adaptado às diferentes formas de organização de poder. Rifkin pondera:

\begin{abstract}
Como todas las personas autónomas que reclamaban soberanía sobre su propiedad personal, el Estado nacional se arrogaba un derecho similar de soberanía sobre el territorio del que formaban parte todos los agentes libres. Y, al igual que sus ciudadanos, el Estado nacional exigía autonomía e igualdad en relación con los otros países y defendía su derecho a proteger las propiedades que estaban bajo su control, así como el de competir con otros Estados nacionales - mediante el comercio o la guerra - por territorios en disputa ${ }^{25}$.
\end{abstract}

Cruz traz que "Soberania se configura como um conjunto de poderes historicamente exercidos pelo Estado e que, em princípio, só a ele correspondem" 26 . E cita Sieyès, que concebeu, racionalmente, o princípio da Soberania da Nação como instrumento de legitimação para a instituição do Estado Constitucional ${ }^{27}$.

território a que pertenciam os agentes livres que o criaram. E, tal como os seus cidadãos, o Estado exigia a autonomia e igualdade em relação a outros países e defendia o seu direito de proteger a propriedade sob seu controle, assim como para competir com outros estados - com comércio ou com guerra em territórios disputados" (tradução livre) RIFKIN, Jeremy. La Civilización Empática, p. 287

26 CRUZ, Paulo Márcio. Fundamentos do direito constitucional. Curitiba: Juruá, 2001. p. 54.

27 CRUZ, Paulo Márcio. Política, Poder, Ideologia e Estado Contemporâneo, p. 67. 
Só que atualmente os movimentos ligados à regionalização abriram fendas significativas no âmbito do Estado. "Essas questões se, de um lado, testam a ordem constitucional, produzem, de outro, a necessidade de desenvolvimento de uma nova compreensão para essas entidades de integração política supranacional"28.

A abertura das economias e das respectivas fronteiras para crescimento das trocas internacionais de mercadorias, dos movimentos de capitais, da circulação de pessoas, de conhecimento e de informação é o que se chama de Globalização e é objeto do próximo tópico.

\section{GLOBALIZAÇÃO}

Não é novidade que a ideia de Globalização esteja associada à expansão cultural ocidental, bem como com a Sociedade capitalista. Independentemente de quem elabora o conceito, não se pensa fora deste contexto.

Como afirma Waters ${ }^{29}$ "a Globalização é a consequência direta da expansão da cultura europeia através do planeta, por via de estabelecimento da colonização e do mimetismo cultural". Visto dessa forma, a conceituação da categoria passa a ter maior importância no seu aspecto econômico, político e cultural.

Para Santos ${ }^{30}$, "a Globalização é, de certa forma, o ápice do processo de internacionalização do mundo capitalista". Assim, entende-se que a Globalização é econômica e, como suas raízes sugerem, envolve conexões que abrangem o mundo.

28 NEVES, Marcelo (Coord.). Transnacionalidade do Direito: novas perspectivas dos conflitos entre ordens jurídicas. São Paulo: Quartier Latin, 2010. p. 245.

29 WATERS, Malcolm. Globalização. Tradução de Magnólia Costa e Ana Bela Rocha. Oeiras, Portugal: Celta, 1999. p. 03. Título Original: Globalization.

30 SANTOS, Milton. Por uma outra Globalização. Do pensamento único à consciência universal. $6 \mathrm{ed}$. Rio de Janeiro: Record, 2001. p. 22.

31 FARIA, José Eduardo. $O$ direito na economia globalizada, p. 52
Faria afirma que Globalização se entende como:

A integração sistêmica da economia em nível supranacional, deflagrada pela crescente diferenciação estrutural e funcional dos sistemas produtivos e pela subsequente aplicação das redes empresariais, comerciais e financeiras em escala mundial atuando cada vez mais independente dos controles políticos e jurídicos ao nível nacional ${ }^{31}$.

Giddens ${ }^{32}$ pondera que a Globalização é "a intensificação de relações sociais em escala mundial que ligam localidades distantes de tal maneira, que acontecimentos locais são modelados por eventos ocorridos a muitas milhas de distância e vice-versa". Desta forma, não se pode entendê-la como uníssona, mas como "uma complexa variedade de processos, movidos por uma mistura de influências políticas e econômicas" 33 .

Já Boaventura Santos ${ }^{34}$ admite que o processo de Globalização é "um fenômeno multifacetado com dimensões econômicas, sociais, políticas, culturais, religiosas e jurídicas interligadas de modo complexo". Trata-se de um processo complexo e por ser complexo perpassa as mais diversas áreas da vida social. Está sedimentado na realidade concreta como resultado de ações econômicas, políticas, e em um determinado espaço e tempo.

Para Gibbons ${ }^{35}$ a Globalização pode ser descrita como "a imitação, adaptação e difusão das inovações tecnológicas, à medida que o processo de industrialização se alastra de um país para outro".

32 GIDDENS, Anthony. A terceira via. Tradução de Maria Luiza X. De A. Borges. 3. Tiragem. Rio de Janeiro: Record, 2000. p. 38.

33 GIDDENS, Antony. As Consequências da Modernidade, p. 45.

34 SANTOS, Boaventura de Souza (org.). A Globalização e as Ciências Sociais. São Paulo: Cortez, 2002. p. 26.

35 GIBBONS, Michael. Globalização, competitividade e o futuro da Educação superior. In: FUNDAÇÃO CALOUSTE GULBENKIAN. Globalização, ciencia, cultura e religiões. Lisboa: Dom Quixote, 2003. p. 241. 
Entendem Teixeira e Diz ${ }^{36}$ que a Globalização é o "resultado de um processo de internacionalização que passa de uma estratégia multidoméstica diversificada para uma estratégia única para todos os países, os quais são vistos como constituindo um único mercado".

Para Habermas ${ }^{37}$ a Globalização encontrase caracterizada como um processo em que se intensificam as relações para além das fronteiras nacionais. Estas relações se dão em nível de comunicação, de trânsito e de transações econômicas. Isto provoca reflexos que se manifestam na forma de se ver o Estado nacional clássico, o entendimento sobre a ideia de Soberania e a legitimidade.

Vê-se, pois, que o conceito de Globalização não é consensual. Como diz Santos, "possui vasto campo de conflitos" 38 . Nesse contexto "pode-se recorrer ao conceito de Globalização, para aludir a indícios de uma 'Globalização' do direito, na qual a relação entre os problemas jurídicas globais e locais, passando pelos estatais, levam a tensões entre ordem jurídicas" 39 .

Cabem as ideias de Castells ${ }^{40}$ quando afirma que, ao se tratar de Globalização, a sua ideia estará associada, principalmente, à economia $^{41}$ nas mais diversas relações e interrelações. Isto porque a base econômica é responsável pelas transformações nas decisões políticas, nas relações comerciais entre as empresas criando mais competitividade assim como alterando níveis de comportamento do comércio regional e internacional.

36 TEIXEIRA, Sebastião. DIZ, Henrique. Estratégias de internacionalização. Lisboa: Publisher team, 2005. p. 91.

37 HABERMAS, Jürgen. A constelação pós-nacional, p. 87.

38 SANTOS, Boaventura de Souza (org.). A Globalização e as Ciências Sociais, p. 27.

39 NEVES, Marcelo (Coord.). Transnacionalidade do Direito: novas perspectivas dos conflitos entre ordens jurídicas, p. 2.

40 CASTELLS, Manuel. Fim do milênio. A era da informação: economia, sociedade e cultura. 5 ed. Tradução de Klauss Brandini Gerhardt e Roneide Venancio Majer.
É de opinião unívoca que a Globalização é um fenômeno que envolve o ser humano em todos os contextos de sua vida, intensificando as relações e encurtando as distâncias, de forma criar uma nova dinâmica econômica e política entre os Estados e diminuindo as distâncias entre as pessoas, o que interfere e avança diretamente na Soberania do Estado.

\section{SUPERAÇÃO DA SOBERANIA}

As características da Globalização vêm flexibilizando a Soberania, pois, apesar de o território continuar existindo sob a regência de normas públicas da alçada nacional, as forças mais ativas do seu dinamismo atual têm origem externa.

Santos apresenta a ideia dos sistemas transgressores que são, sobretudo, a informação e a finança:

A fluidez se multiplica graças às maravilhas da técnica contemporânea. Mas é um equívoco pensar que a informação e a finança exercem sempre sua força sem encontrar contrapartida interna. Esta depende de uma vontade política interior, capaz de evitar que a influência dos ditos fatores seja absoluta $^{42}$.

Modernamente Saskia Sassen escreve que: "Today, it is becoming evident that even as national territories remain bound by traditional geographic borderlines, globalization is causing novel types of 'borderings' to multiply"43.

Ainda Saskia Sassen:

São Paulo: Paz e terra, 2009. v.3.

41 "A dimensão principal do processo de Globalização diz respeito aos mercados financeiros e mercados monetários" CASTELLS, Manuel. Fim do milênio. A era da informação: economia, sociedade e cultura. v.3. p. 393.

42 SANTOS, Milton. Por uma outra Globalização, p. 77.

43 "Hoje, torna-se evidente que, mesmo com territórios nacionais vinculadas por fronteiras geográficas tradicionais, a Globalização está causando novos tipos de fronteiras" (tradução livre) SASSEN, Saskia. Bordering Capabilities versus Borders: Implications for National Borders. In: 30 Michigan Journal of International Law (2008-2009). p. 567 
[The] State plays an active role in this denationalizing, but this only becomes evident when we disaggregate 'the' State and examine the work of particular parts of the State: particular agencies, particular court decisions, particular executive conditions. It also means that this denationalizing can coexist with traditional borders and with the ongoing role of the State in new global regimes ${ }^{44}$.

Todavia, essa flexibilização da Soberania não é algo natural e automático, porque depende da forma como o governo de cada país decide adequar sua ordem jurídica e se inserir no mundo globalizado. Exemplo claro disso é a participação de alguns países na União Europeia. A Dinamarca e o Reino Unido enquadram-se em casos excecionais no tratado original de Maastricht. Ambos estão isentos de se juntar à Zona Euro a não ser que um voto parlamentar ou referendo decida o contrário. A Dinamarca planeja realizar um referendo popular após certos trâmites legais relacionados ao Tratado de Lisboa. A Suécia obteve a exceção de fato porque não possui os critérios necessários para a adoção da moeda única. Além disso, o povo sueco rejeitou o euro através de referendo.

É perceptível atualmente a crise do paradigma do Estado Moderno, pautado pelas fronteiras nacionais, que determinou o modo de ser e agir do ser humano, nos séculos XIX e XX. Parafraseando Cruz e Bodnar, o fim do contraponto socialista e a hegemonização do capitalismo liberal erodiram sua principal característica, ou seja, a Soberania herdada da paz da Westfália ${ }^{45}$.

Não se olvide:

44 "[O] Estado desempenha um papel ativo nesta desnacionalização, mas isso só fica evidente quando desagregamos "o" Estado e examinamos o trabalho de partes específicas do Estado: agências particulares, decisões judiciais específicas, condições específicas de executivos. Isso também significa que esta desnacionalização pode coexistir com as fronteiras tradicionais e com o papel do Estado em curso em novos regimes globais" (tradução livre) SASSEN, Saskia. Bordering Capabilities versus Borders: Implications for National Borders, p. 569.
A crise da liberdade como paradigma do direito moderno se iniciou com as lutas pelo Estado Social, no final do século XIX e no começo do século XX. Foram as ideias $\mathrm{e}$ as ações socialistas que pressionaram as sociedades europeias a admitir a flexibilização dos paradigmas do Estado Liberal e do direito moderno (Wolkmer, 1996, p. 26). As sociedades ocidentais passaram a conferir um evidente equilíbrio entre os dois conceitos: Estado de Liberdade e Estado de Igualdade ${ }^{46}$.

Nesse contexto que reconhece o enfraquecimento dos Estados nacionais Modernos e o fenecimento das fronteiras, a Globalização ${ }^{47}$ fica fortalecida nas organizações internacionais de cooperação e integração regional com a superação da Soberania tida por moderna. Como exemplo, cita-se novamente a União de Nações Sul-Americanas - UNASUL que é uma organização intergovernamental composta pelos doze estados da América do Sul, fundada dentro dos ideais de integração sulamericana multissetorial, conjugando as duas uniões aduaneiras regionais: o Mercado Comum do Sul (Mercosul) e a Comunidade Andina de Nações (CAN). É composta por Argentina, Bolívia, Brasil, Chile, Colômbia, Equador, Guiana, Paraguai, Peru, Suriname, Uruguai e Venezuela.

A diminuição da Soberania estatal acarreta uma série de crises em outros institutos e instituições. Estuda-se crise do Direito Nacional, a superação da Democracia e a crise mesmo do modelo de Estado. Cruz e Oliviero sintetizam essas crises assim:

45 CRUZ, Paulo Márcio; BODNAR, Z. O novo paradigma de Direito na pós-modernidade. Porto Alegre. RECHTD/UNISINOS. RECHTD. Revista de Estudos Constitucionais, Hermenêutica e Teoria do Direito, v. 3, p. 75-83, 2011. p. 76.

46 Ibid., p. 78.

47 ANJOS FILHO, Robério Nunes dos (ORG.). Globalização, justiça e segurança humana. Brasília: ESMPU, 264p. 
A brecha jurisdicional, que não é mais que a discrepância entre um mundo globalizado e as unidades nacionais relativas à formulação de normas; a brecha da participação de novos atores e cidadãos nos espaços de governança transnacional, ou seja, na extensão transnacional da democracia; e a brecha dos incentivos, entendidos como mecanismos de ajuda aos países em desenvolvimento para fazer efetiva a cooperação internacional $^{48}$.

Para a crise do Direito, Cruz e Oliviero propõe o Direito Transnacional. Isso porque Direito Moderno (nacional e internacional) não tem gerado mecanismos eficazes de governança, regulação, intervenção e coerção para as demandas transnacionais. "Também o Direito Comunitário, que regula uma das manifestações da nova ordem mundial, caracterizada por novas relações e novas manifestações de atores e instituições, não apresenta bases teóricas suficientes para a caracterização de um ou mais espaços públicos transnacionais"49. Um exemplo desse problema é o Tribunal Penal Internacional - TPI, criado pelo Estatuto de Roma, que entrou em vigor internacional em 1-7-2002 e foi ratificado pelo Brasil em 20-6-2002, passando a ser parte e assumindo as obrigações dele decorrentes. As críticas que se faz são que o poder político do sistema internacional torna ineficaz o TPI, o princípio da jurisdição complementar, em que só há processo se o país do conflito não tiver instituições políticas e judiciais estáveis e eficientes para presidir um julgamento e que o modus operandi dos conflitos atuais mostram que a execução sumária de inimigos tem sido muito mais praticada do que sua submissão a tribunais internacionais, mesmo por países que a ele aderiram.

É que, "atualmente, o Estado não consegue mais dar respostas consistentes à Sociedade diante

48 CRUZ, Paulo Márcio; FERRER, G. R. Os novos cenários transnacionais e a democracia assimétrica - Porto Alegre - RECHTD - UNISINOS. RECHTD. Revista de Estudos Constitucionais. p. 107. da complexidade das demandas transnacionais que se avolumam continuamente. Os problemas sociais aumentam em proporções preocupantes"50.

Da mesma forma, Cruz e Ferrer vão além e dizem que, em razão da Globalização e flexibilização da Soberania, atualmente, o que está em jogo é a própria Democracia. Isso porque:

\begin{abstract}
A Globalização rompe seu habitat natural - um território delimitado por fronteiras, dentro das quais vivem determinados cidadãos - e, ao mesmo tempo, gera exclusão social, indo contra a raiz de toda ordem democrática, negando a cidadania. Não se deve perder de vista que o processo de Globalização em curso não só tem caráter econômico, mas muito fundamentalmente caráter político, ainda que formalmente não se apresente assim (Oller I Sala, 2002). Por trás de um viés economicista se esconde uma orientação política muito concreta, ou melhor, dizendo uma forma de dominação que, disfarçada de apolítica, expulsa os cidadãos para um mundo de redes anônimas que escapam de todo controle e a toda lógica democrática. Este mundo das redes está dominado pelas grandes empresas transnacionais, administradoras de uma economia global que tende ao oligopólio na maioria dos setores. Estas empresas estão, além disso, abertamente aliadas ao poder estatal na sua tarefa de socialização do risco e do custo, assim como na repressão àquilo que não seja politicamente correto $^{51}$.
\end{abstract}

\section{A transnacionalização da Democracia} exigirá uma limitação da Soberania dos estados, mas essa limitação não deve ser exercida por outros estados. Nenhum Estado está autorizado a condicionar a Soberania dos demais estados. Citase, pois, a conduta da empresa Wikileaks ao divulgar relatórios secretos, obtidos por meio de invasão em sistemas de segurança da Casa Civil e da Presidência da República, para mencionar apenas os efeitos da ação no Brasil. É que a internalização causa uma restrição de fato da soberania, que passa a ser formal e não material,

49 CRUZ, Paulo Márcio; OLIVIERO, Maurizio. Reflexões Sobre o Direito Transnacional. Itajaí/Perugia. Novos Estudos Jurídicos (Online), v. 17, 2012. p. 5.

50 Ibid., p. 5.

51 CRUZ, Paulo Márcio; FERRER, G. R. Os novos cenários transnacionais e a democracia assimétrica, p. 101. 
já que seu conteúdo é cada vez mais diminuído pela criação e desenvolvimentos das organizações internacionais. A imposição de uma decisão do coletivo internacional ao ente estatal que define não obedecê-la constitui ingerência indevida nos assuntos internos desse Estado, pois tem caráter impositivo ou coercitivo.

Então, “este emergente poder político transnacional deve, por outro lado, facilitar o surgimento de espaços públicos de governança transnacionais articulados em torno de bens mundiais" ${ }^{52}$. O que se mantém ainda são as fronteiras. "Estas fronteiras estão a ser subvertidas por bens culturais transcendestes que não as respeitam ${ }^{53}$ ".

A realidade da Globalização no aspecto econômico subverte esta ordem, faz com que a parte se subordine ao todo. Igualmente a Globalização no aspecto político, isto é, de nação, com base no cidadão também subverte esta ordem ao considerar os princípios e fundamentos que são gerais como, por exemplo, a segurança, o meio ambiente, direitos humanos e redução da violência em necessidades humanas globais.

Hodiernamente, verifica-se como a capacidade dos sistemas jurídicos estatais de produzir o próprio direito em forma absoluta está gradualmente se redimensionando, reformulando a própria categoria histórica da Soberania nacional na direção de uma definição conceitual ainda de híbrida caracterização, de modo a vergar o conceito de Democracia.

Isso ocorre porque as próprias opções políticas abertas às maiorias parlamentares encontram-se sempre mais circunscritas à constante cessão de Soberania à comunidade internacional ou transnacional, principalmente por meio de instituições como o Fundo Monetário Internacional (FMI), a Organização das Nações

52 Ibid., p. 107.

53 WATERS, Malcolm. Globalização, p. 118.

54 Ibid., p. 2.
Unidas (ONU) e as suas agências e mesmo as grandes corporações transnacionais privadas que antes eram denominadas multinacionais. Com isso, algumas opções políticas se tornam impraticáveis,

[...] a não ser forçando as barreiras de uma espécie de "estado de necessidade econômica" produzido pela influência irresistível desses grandes grupos econômicos de significância mundial transnacional que, como sabemos, são muito mais poderosos que muitos Estados e capazes de modificar as características estruturais das próprias democracias contemporâneas. Tais grupos, efetivamente, não apenas dominam quase toda a cena política mundial, mas também capturam as suas legislações, condicionando-as, em nome das exigências de mercado e de desenvolvimento ${ }^{54}$.

Daí que surge o Direito Transnacional, que seria desterritorializado e destinado a limitar poderes transnacionais sem uma base física definida, o que é uma das circunstâncias que molda o cenário transnacional, especialmente porque diz respeito ao aspecto além-fronteira.

No sentido mais estreito "a mesma expressão refere-se a ordens jurídicas transnacionais no sentido proposto por Teubner, que aponta para ordens normativas privadas que surgem e se desenvolvem no plano global independentemente tanto do Estado e de suas fronteiras quanto de ordens construídas com base em Estados, ou seja, supranacionais e internacionais" $" 55$.

Não é o espaço estatal nacional e também não é espaço que está acima dele ou entre eles. "Está para todos eles ao mesmo tempo, ou seja, desvinculado da delimitação precisa do âmbito territorial em que o Direito Nacional tenta exercer Soberania e tenta impor coercitivamente as suas leis" 56 .

55 NEVES, Marcelo (Coord.). Transnacionalidade do Direito: novas perspectivas dos conflitos entre ordens jurídicas, p. 2.

56 CRUZ, Paulo Márcio; FERRER, G. R. Os novos cenários transnacionais e a democracia assimétrica, p. 7 . 
Jessup diz que o Estado não é o único grupo que nos interessa:

Os problemas a examinar, são em grande parte, os comumente chamados internacionais, e o direito a se aplicar consiste nas normas a eles aplicáveis. Mas o termo "internacional” é enganador, já que sugere que nos preocupamos apenas com as relações de uma Nação (ou Estado) com outras Nações (ou Estados). [...]

Em lugar de "direito internacional" a expressão "direito transnacional", para incluir todas as normas que regulam atos ou fatos que transcendem fronteiras nacionais. Tanto o direito público quanto o privado estão compreendidos, como estão outras normas que não se enquadram inteiramente nessas categorias clássicas ${ }^{57}$.

Logo, vê-se que o caminho que se abre para a Democracia no século XXI é bem estreito e longo. Isso porque:

A Globalização obriga a recuperar a reflexão sobre a Democracia dos Estados modernos e a se perguntar pelas questões de seus fundamentos, as instituições que garantem seu exercício e seus limites em contextos sociais diferentes" ${ }^{\circ 8}$.

Não se pode perder de vista que

A existência do capitalismo transnacional e suas crises é uma realidade muito difícil de ser questionada, assim como é difícil negar a existência de uma nova produção integrada e de um novo sistema financeiro global. Como escreve Michel Bachelet, a menos que a sociedade mundial aperfeiçoe e, sobretudo, aplique as normas de uma solidariedade multissetorial à escala de todos os habitantes do planeta, populações inteiras desaparecerão pura e simplesmente pelos efeitos conjugados das doenças ligadas à desnutrição e dos jogos da economia mundial. Ou de uma "irresponsabilidade organizada", expressão utilizada por Urich Beck ${ }^{59}$.

Um tema bastante recorrente e atual quando discute a crise da Democracia é o dos refugiados que tem imigrado para a Europa. A dúvida que surgirá daqui a alguns anos é qual lei aplicar aos

57 JESSUP, Philip C. Direito Transnacional. Tradução de Carlos Ramires Pinheiro da Silva. São Paulo: Fundo de Cultura, 1965. p. 11-12. filhos nascidos nos países ocupados. É aquele Direito que se cria em vários locais do mundo, fora do território de determinado Estado, mas o influencia, o que demonstra a superação do conceito de território, flexibilização da Soberania e embrenhamento do campo da Transnacionalidade.

No mesmo sentido, fala-se, por exemplo, em direito esférico, quando novas tecnologias aumentam a velocidades das sinapses da sociedade e provocam mudanças no comportamento e no andamento das instituições, porém o mecanismo legislativo de regulação não acompanha tais mudanças. Assim, nota-se uma nítida transformação da pirâmide de Kelsen, e o Direito passaria a não ser mais hierarquizado ou compartimentalizado, mas, sim, esférico, na medida em que deve conviver com a ampliação dos limites espaciais e temporais, a confusão de planos nacional e internacional, a queda do princípio da hierarquia normativa, forte dependência do conhecimento científico e multiplicação de fontes e a variação de fundamentos de legitimidade do ordenamento jurídico.

O paralelismo existente entre a possibilidade de se identificar tendências globais que admitem a democracia transnacional e a ausência de uma teoria plausível sobre as condições de sua criação permeiam o ambiente transnacional. Nas palavras de Held:

This involves consideration of two issues: the extent
to which it is possible to identify immanent
tendencies in global politics which provide the
conditions for its potential realization; and theextent
to which any of the theories of transnational
democracy provide a plausible or persuasiv e
account of the conditions of its possibility
(Hutchings, 1999). These are necessarily issues
which are likely to generate radically divergent 58 CRUZ, Paulo Márcio; FERRER, G. R. Os novos cenários transnacionais e a democracia assimétrica, p. 99. 59 CRUZ, Paulo Márcio; OLIVIERO, Maurizio. Reflexões Sobre o Direito Transnacional, p. 9. 
conclusions for they invite speculative judgments and are inseparable from prior ethical convictions ${ }^{60}$.

Não é outro o viés apresentado por Cassese, segundo o qual:

Da un lato, c'è il problema della legittimazione democratica dei poteri pubblici globali. Dall'altro, c'è la questione dei poteri pubblici globali come veicolo della democratizzazione dei poteri pubblici nazionali. Anche sotto questo profilo, insomma, non si può isolare un 'livello globale', staccandolo dai poteri pubblici nazionali ${ }^{61}$.

Ainda há muito a ser debatido sobre as formas e condições inéditas de ocupação do espaço público e do ativismo político transnacional diante da superação da Soberania.

Os novos debates sobre a construção de uma esfera pública não estatal impõem a discussão sobre a crise do Direito Moderno e da democracia diante da Globalização e da superação da Soberania com a desconstrução da ideia de Estado nacional.

\section{CONCLUSÃO}

O Estado, que havia sido erigido sobre os conceitos de povo território e Soberania, passa agora a sofrer a concorrência de outras universalidades (o mercado, as empresas, o governo, os grupos, os sistemas de informação, as tecnologias etc.).
A Soberania, definida inicialmente como um conjunto de poderes exercidos com exclusividade pelo Estado, não encontra guarida no mundo contemporâneo diante da Globalização.

A Sociedade como um todo encontra-se envolvida no processo de Globalização e cada vez com mais intensidade. $\mathrm{O}$ grande embate passa a ser politizar a Globalização para que seus espontâneos processos econômicos e sociais constituam um progresso civilizatório, de modo a superar crises do Direito Nacional, da Democracia e mesmo do modelo de Estado Moderno.

Diante da inevitável Globalização e da inescondível crise, a Soberania estatal verga-se a ponto de fazer surgir o Direito Transnacional, que tutela bens jurídicos acima de fronteiras e é desvinculado da delimitação precisa do âmbito territorial.

É necessário manter o mundo em ordem, no qual Estados e instituições, em maior ou menor grau, continuem a cooperar e competir dentro de um espaço mundialmente normatizado.

\section{REFERÊNCIAS}

60 "Isso envolve a consideração de duas questões: na medida em que é possível identificar tendências imanentes em políticas globais que fornecem as condições para a sua realização potencial; e na medida em que nenhuma das teorias da democracia transnacional fornece um relato plausível ou persuasivo das condições de sua possibilidade (Hutchings, 1999). Estas são necessariamente questões que são suscetíveis de gerar conclusões radicalmente divergentes e convidam a julgamentos especulativos, inseparáveis de convicções éticas anteriores" (tradução livre) HELD, David. MCGREW, Tony. Transnational Democracy: Theories and Prospects. Global Transformations. Disponível em: < https://www.polity.co.uk/global/transnational-democracytheories-and-prospects.asp\#economic >. Acesso em: 2 fev. 2016.

61 "Por um lado, há o problema da legitimidade democrática dos poderes públicos globais. Por outro, há a questão dos poderes públicos como meio de democratização mundial dos governos nacionais. Também a este respeito, em suma, não é possível isolar um 'global', soltando-a dos governos nacionais” (tradução livre) CASSESE, Sabino. Globalizzazione del diritto. Disponível em: http://www.treccani.it/enciclopedia/globalizzazione-deldiritto_(XXI-Secolo)/ Acesso em: 2 fev.2016. 
ANJOS FILHO, Robério Nunes dos (ORG.). Globalização, justiça e segurança humana. Brasília: ESMPU.

BLUNTSHLI, J. Johann Kaspar. The theory of the State. Oxford: Clarendon Press, 1898.

BOBBIO, Norberto. Estado governo e Sociedade. Trad. Marco Aurélio Nogueira. 4.Ed. Rio de Janeiro: Paz e Terra, 1992.

BRANCO. Elcir Castello. Teoria geral do Estado. São Paulo: Saraiva, 1988.

CAETANO, Marcello. Manual de Ciência Política e Direito Constitucional. 4 ed. Lisboa: Coimbra Editora,1963.

CASSESE, Sabino. Globalizzazione del diritto. Disponível em: <http://www.treccani.it/enciclopedia/globalizzazione-del-diritto_(XXI-Secolo)>. Acesso em: 2 fev. 2016.

CASTELLS, Manuel. Fim do milênio. A era da informação: economia, sociedade e cultura. 5 ed. Tradução de Klauss Brandini Gerhardt e Roneide Venancio Majer. São Paulo: Paz e terra, 2009. v.3.

CRUZ, Paulo Márcio Cruz. Política, poder, ideologia e Estado contemporâneo. Florianópolis, Diploma Legal. 2001.

CRUZ, Paulo Márcio. Fundamentos do direito constitucional. Curitiba: Juruá, 2001.

CRUZ, Paulo Márcio; BODNAR, Z. O novo paradigma de Direito na pós-modernidade. Porto Alegre. RECHTD/UNISINOS. RECHTD. Revista de Estudos Constitucionais, Hermenêutica e Teoria do Direito, v. 3, p. 75-83, 2011.

CRUZ, Paulo Márcio; FERRER, G. R. Os novos cenários transnacionais e a democracia assimétrica. Porto Alegre - RECHTD - UNISINOS. RECHTD. Revista de Estudos Constitucionais, Hermenêutica e Teoria do Direito, v. 2, p. 96-111, 2010.

CRUZ, Paulo Márcio; OLIVIERO, Maurizio. Reflexões Sobre o Direito Transnacional. Itajaí/Perugia. Novos Estudos Jurídicos, v. 17, 2012.

DALLARI, Dalmo de Abreu. Elementos de Teoria geral do Estado. 19. Ed. São Paulo: Saraiva, 1995.

FARIA, José Eduardo. O direito na economia globalizada. São Paulo: Malheiros, 2004.

FERRER, Gabriel Real. Anotações de aula da disciplina Governança Transnacional $E$ Sustentabilidade, ministrada em 23 de setembro de 2015, no auditório da Universidade do Vale do Itajaí - Univali, no auditório do Programa de Pós-Graduação stricto sensu em Ciência Jurídica, para o Curso de Doutoramento em Ciência Jurídica.

FERRER, Gabriel Real. Sostenibilidad, transnacionalidad y trasformaciones del Derecho. Revista de Derecho Ambiental, Abeledo Perrot, Buenos Aires, n. 32, outubro-dezembro 2012, p. 65-82; e em 
Maria Cláudia da Silva Antunes de Souza e Denise Schmitt Siqueira Garcia (Orgs.), Direito Ambiental, Transnacionalidade e Sustentabilidade, Univali editora, Itajaí, 2013.

GIBBONS, Michael. Globalização, competitividade $e$ o futuro da Educação superior. In: FUNDAÇÃO CALOUSTE GULBENKIAN. Globalização, ciencia, cultura e religiões. Lisboa: Dom Quixote, 2003.

GIDDENS, Anthony. A terceira via. Tradução de Maria Luiza X. De A. Borges. 3. Tiragem. Rio de Janeiro: Record, 2000.

GIDDENS, Anthony. As consequências da modernidade. 2 ed. Tradução de Fernando Luís Machado e Maria Manuela Rocha. Oeiras: Celta Editora, 1995. Título original: The consequences of modernity.

GRILLO, Vera de Araújo. A separação dos poderes no Brasil: Legislativo versus Executivo. Blumenau; Itajaí: Editora Edifurb; Editora Univali, 2000.

HABERMAS, Jürgen. A constelação pós-nacional: Ensaios políticos. Tradução de Márcio Seligmann Silva. São Paulo: Littera Mundi, 2001.

HELLER, Hermann. Teoría del Estado. 2. Ed. Tradução de Luis Tobio. México: Fondo de Cultura Económica, 1998. Título original: Staatslehre.

JELLINEK, Georg. Teoría General Del Estado. Tradução de Fernando de Los Rios. Buenos Aires: Albatroz, 1978. Título original: Allgemeine Staatslehre.

JESSUP, Philip C. Direito Transnacional. Tradução de Carlos Ramires Pinheiro da Silva. São Paulo: Fundo de Cultura, 1965.

KELSEN, Hans. Teoria pura do direito. Tradução de João Baptista Machado. 7. ed. São Paulo: Martins Fontes, 2006.

MATTEUCCI, Nicola; PASQUINO, Gianfranco. Dicionário de Política. Tradução de Carmen C. Varrialle et alli. 8. ed. Brasília: Universidade de Brasília, 1995. Título original: Dizionário di Politica. v. 2. p. 1179-1188.

MIRANDA, Jorge. Teoria do Estado e da Constituição. 2 ed. Rio de Janeiro: Forense, 2009.

NEVES, Marcelo (Coord.). Transnacionalidade do Direito: novas perspectivas dos conflitos entre ordens jurídicas. São Paulo: Quartier Latin, 2010.

OLIVIERO, Maurizio. Anotações de aula da disciplina Teoria do Estado e da Constituição, ministrada em 21 de setembro de 2015, no auditório da Universidade do Vale do Itajaí - Univali, no auditório do Programa de Pós-Graduação stricto sensu em Ciência Jurídica, para o Curso de Doutoramento em Ciência Jurídica.

RIFKIN, Jeremy. La Civilización Empática. Tradução de Vanessa Casanova e Genis Sanchez Barberan. Barcelona: Ediciones Paidós, 2014. 
SANCHES, Luiz Antonio Ugeda. $O$ que é o Geodireito? Disponível em: <http://operariododireito.blogspot.com.br/2010/03/o-que-e-o-geodireito-por-luiz-antonio.html>. Acesso em: 24 set. 2015.

SANTOS, Boaventura de Sousa. Pela mão de Alice: o social e o político na pós- modernidade. 9. e. São Paulo: Cortez, 2001.

SANTOS, Boaventura de Souza (org.). A Globalização e as Ciências Sociais. São Paulo: Cortez, 2002.

SANTOS, Milton. Por uma outra Globalização. Do pensamento único à consciência universal. 6 ed. Rio de Janeiro: Record, 2001.

SASSEN, Saskia. Bordering Capabilities versus Borders: Implications for National Borders. 30 Michigan Journal of International Law, p. 567-597, 2008-2009.

SOARES, Mário Lúcio Quintão. Teoria do Estado: novos paradigmas em face da Globalização. 4. ed. São Paulo: Atlas, 2011.

TEIXEIRA, Sebastião, DIZ, Henrique. Estratégias de internacionalização. Lisboa: Publisher team, 2005.

WATERS, Malcolm. Globalização. Tradução de Magnólia Costa e Ana Bela Rocha. Oeiras, Portugal: Celta, 1999. Título Original: Globalization.

Recebido em: 14/02/2016

Aceito em: 25/06/2016 
